Pak. j. sci. ind. res. Ser. A: phys. sci. 2020 63A(2) 71-78

\title{
Colorimetric Determination of Paracetamol Using 9-Chloroacridine Reagent: Application to Pharmaceutical Formulations
}

\author{
Firas Hassan Awad \\ Department of Pathological Analysis, Al-Qalam University College, Iraq
}

(received February 26, 2019; revised June 24, 2019; accepted June 26, 2019)

\begin{abstract}
This paper aims to develop a simple, sensitive and accurate spectrophotometric method for quantitative determination of paracetamol in aqueous medium. The method is based on the reaction between the hydrolyzed paracetamol and 9-chloroacridine reagent (9-CA). The spectra of the product show maximum absorption at $436 \mathrm{~nm}$. Beer's law is obeyed in the concentration range of $0.25-11 \mu \mathrm{g} / \mathrm{mL}$ with molar absorptivity value $5.3 \times 10^{3} \mathrm{~L} / \mathrm{mol} / \mathrm{cm}$. The average recovery percentage ( $\mathrm{Rec} \%$ ) is $99.27 \%$ and relative standard deviation (RSD) is $\leq 2.82 \%$. In addition, the stability constant has been determined and the reaction mechanism is proposed. The method has been applied successfully for the assay of paracetamol in pharmaceutical formulations. It is found that the method does not require extraction process and it agree well with British pharmacopeia.
\end{abstract}

Keywords: paracetamol, 9-chloroacridine, spectrophotometry

\section{Introduction}

Paracetamol (acetaminophen, $\mathrm{N}$-acetyl-p-aminophenol, 4-acetamido phenol) is official in the United States (United States Pharmacopoeia, 2013) and British (British Pharmacopoeia, 2009). European, (European Pharmacopoeia, 2014) and Japanese (Japanese Pharmacopoeia, 2016). The pharmacopoeias are widely used for minor analgesic and antipyretic agent (Sharma and Mehta, 2014). Paracetamol action is similar to aspirin and it is the most commonly used in paediatrics (Hamm, 2000) although it has some cyclo-oxygenase inhibiting properties. Paracetamol is a synthetic non opiate derivative of $p$-aminophenol and is hydrolyzed inappropriate storage conditions such as high temperatures and acidic or basic media to $p$-aminophenol (Chen et al., 2002). It is a harmful compound for humans because it increases body temperature and remains active for a long time (Song and Chen, 2001).

The majority of published spectrophotometric methods for determination of paracetamol depends on hydrolysis of the compound and applying oxidative coupling (Al-Esawati, 2002; Al-Ward, 2002; Afshari and Liuo, 2001; Tetsuo et al., 1975) and diazotization coupling (Raymond et al., 2017; Shrestha and Pradhananga, 2009; Al-Abachi et al., 2008) and the methods leading to the determination of produced $p$-aminophenol by

*Author for correspondence;

E-mail: firasalbdrany@yahoo.com different reagents, in addition to using of other methods such as Schiff bases formation (Nagendra, 2011), oxidation reaction (Kumar et al., 2012; Sultan et al., 1986) and charge transfer complex formation reactions (Divya et al., 2013; Al-Enizzi, 2002). However, some of these methods were either not sensitive (Kumar et al., 2012), carried in organic medium (Divya et al., 2013) or suffered from interferences (Liu and Oka, 1980). Other analytical techniques have been also used for determination of paracetamol, such as HPLC (Darak et al., 2012; Pastorini et al., 2008), voltammetry (Tungkananuruk et al., 2005; Nigoviæ and Simuniæ, 2003), chemilumi-nescence (Ruengsitagoon et al., 2006; Easwaramoorthy et al., 2001). These methods need of highly sophisticated instruments. In addition to the titrimetric method that is not sensitive (Muszalska, 2000). The present work describes a simple and sensitive spectrophotometric method for analysis of paracetamol. The method is based on the formation of a coloured product by the reaction of hydrolyzed paracetamol with 9-CA as chromogenic reagent without any derivatization or catalysis.

\section{Materials and Methods}

Spectra and absorbance measurements were made with UV-visible double beam spectrophotometers (PerkinElmer, lambda 25) and with $1 \mathrm{~cm}$ matched silica cells. The $\mathrm{pH}$ measurements were made by using Cyber Scan 510 pc. pH meter with a combined glass electrode. 
Heating of solutions is carried out on a water bath of (FROST Instruments, LTD). Weighing is carried out on a sensitive balance type of Mettler H 54AR. All calculations in the computing process were done in Microsoft Excel 2010.

Reagents. All chemicals used are of high purity provided by (BDH, Fluka and Molekula chemical companies). 9-Chloroacridine (Eastman Chemical Company) was used as the chromogenic reagent. Absolute ethanol is used (ROTH chemical company). Sodium hydroxide $\left(1 \times 10^{-2} \mathrm{M}\right)$ and hydrochloric acid $\left(1 \times 10^{-2} \mathrm{M}\right)$ solution are prepared by appropriate dilution of the concentrated $\mathrm{NaOH}(1 \mathrm{M})$ or $\mathrm{HCl}(1 \mathrm{M})$ solutions with distilled water. 9-chloroacridine (9-CA) reagent $\left(1 \times 10^{-3} \mathrm{M}\right)$. The $25 \mathrm{~mL}$ solution is prepared by dissolving $0.0053 \mathrm{~g}$ of 9-chloroacridine in ethanol absolute and then the volume is completed to $25 \mathrm{~mL}$ in a volumetric flask. The solution is prepared daily and used immediately (Ruengsitagoon et al., 2006).

A solution of hydrolyzed paracetamol $(25 \mu \mathrm{g} / \mathrm{mL})$. $2000 \mu \mathrm{g} / \mathrm{mL}$ solution was prepared by dissolving 0.20 $\mathrm{g}$ of pure paracetamol in $10 \mathrm{~mL}$ ethanol and shaking to increase the solubility, then filtered into $100 \mathrm{~mL}$ calibrated flask and the solution was completed to the volume with a distilled water (the solution was equivalent to $2000 \mu \mathrm{g} / \mathrm{mL}$ paracetamol). $75 \mathrm{~mL}$ of this solution was transferred into $250 \mathrm{~mL}$ round bottom flask provided with condenser and $25 \mathrm{~mL}$ of conc. hydrochloric acid was added then reflux for $1 \mathrm{~h}$. After that, the cold solution was neutralized by $4.5 \mathrm{~mL}$ of $20 \%$ sodium carbonate and diluted to $250 \mathrm{~mL}$ with distilled water in a volumetric flask. To prepare $25 \mu \mathrm{g} / \mathrm{mL}$ paracetamol, $4.16 \mathrm{~mL}$ of the above solution was diluted to $100 \mathrm{~mL}$ in a volumetric flask using distilled water.

Recommended procedure. To a series of $5 \mathrm{~mL}$ calibrated flasks, increasing volumes of the working hydrolyzed paracetamol solution $(25 \mu \mathrm{g} / \mathrm{mL})$ were transferred to cover the concentration range 0.25-11 $\mu \mathrm{g} / \mathrm{mL}$, add $2 \mathrm{~mL}$ of $1 \times 10^{-3} \mathrm{M} 9$-CA. The solutions were diluted to the mark with absolute ethanol. The solutions were kept at $40{ }^{\circ} \mathrm{C}$ for $30 \mathrm{~min}$ in a water bath and the absorbance was measured at $436 \mathrm{~nm}$ against reagent blank after cooling to room temperature.

Procedure for paracetamol assay in tablet and suspension. Tablet. Ten tablets of paracetamol were weighed and finely powdered. A weighed amount of the powder $0.2 \mathrm{~g}$ of paracetamol was dissolved in 10 $\mathrm{mL}$ ethanol and diluted to the mark in $100 \mathrm{~mL}$ calibrated flask, then followed the above procedure of acid hydrolysis of paracetamol. $16.7 \mathrm{~mL}$ of the resulting solution was diluted to $100 \mathrm{~mL}$ in a volumetric flask using distilled water to obtain $100 \mu \mathrm{g} / \mathrm{mL}$.

Suspension solution. A $10 \mathrm{~mL}$ of syrup (each $5 \mathrm{~mL}$ contain $125 \mathrm{mg}$ paracetamol) was transferred into a 250 $\mathrm{mL}$ calibrated flask and the total volume was diluted with distilled water and required the procedure as mentioned in hydrolyzed paracetamol solution from tablets.

\section{Results and Discussion}

In the preliminary investigation work, it was found that 9-CA reagent reacted selectively with paracetamol after hydrolyzed paracetamol, in an alcoholic medium of ethanol and produced a yellowish-green coloured solution immediately with maximum absorption at $436 \mathrm{~nm}$. The intensity of this colour increased when the reaction mixture was heated and in contrast to the reagent blank which shows maximum absorption at $390 \mathrm{~nm}$ (Fig. 1). However, the wavelength of maximum absorption at $436 \mathrm{~nm}$ was used in all subsequent experiments.

The optimum conditions. The effect of various parameters on the absorption intensity of the coloured 9-CA-hydrolyzed paracetamol product has been investigated and the reaction conditions have been optimized.

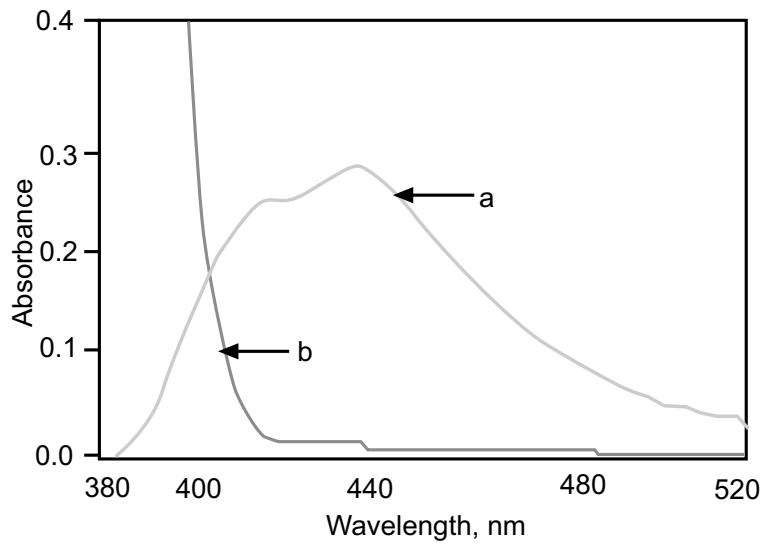

Fig. 1. Absorption spectra of (a) hydrolyzed paracetamol $(6.0 \mu \mathrm{g} / \mathrm{mL})$ product with 9$\mathrm{CA}\left(1 \times 10^{-3} \mathrm{M}\right)$ against reagent blank and (b) reagent blank against ethanol at optimum conditions. 
Effect of $\boldsymbol{p H}$. The effect of $\mathrm{pH}$ on the colour intensity at the range between 2.51 and $11.35 \mathrm{pH}$ value was studied, by addition of $0.01 \mathrm{M}$ of $\mathrm{HCl}$ and $\mathrm{NaOH}$. It was found that the sensitivity of the product was not affected by $\mathrm{HCl}$ addition but decreased in the presence of $\mathrm{NaOH}$. However, the $\mathrm{pH}$ of the final dilution was measured in the absence of $\mathrm{HCl}$ and $\mathrm{NaOH}$ and found to be 9.42. Different buffer solutions (bicarbonate, borate and phosphate of $\mathrm{pH} 9.42$ ) were also examined. These showed a negative effect on the absorbance of the product 9 (Fig. 2).

Effect of reagent concentration. Different volumes of $\left(1 \times 10^{-3} \mathrm{M}\right) 9$-CA were added to a solution containing $2.5 \mu \mathrm{g} / \mathrm{mL}$ of paracetamol in a final volume of $5 \mathrm{~mL}$. The absorbance was measured at $436 \mathrm{~nm}$ after $10 \mathrm{~min}$ at room temperature against reagent blank. It was evident that the absorbance increases with increasing reagent concentration and reached maximum on using a volume of 2.0-3.0 mL of 9-CA (Fig. 3) and $2 \mathrm{~mL}$ was selected in the subsequent experiments.

Effect of surfactants. Effect of various surfactants including SDS, CTAB, Tween- 80 and Triton $\mathrm{x}-100$, of $0.2 \%$ concentration, on the absorption intensity of the paracetamol-9-CA product has been investigated as shown in Fig. 4, there is a negative effect of these surfactants on the absorbance of paracetamol-9-CA product.

Effect of temperature and time. The effect of temperature on the rate of reaction for paracetamol-9-CA product was studied at room temperature $\left(22^{\circ} \mathrm{C}\right), 40$ and $50{ }^{\circ} \mathrm{C}$ at the previous optimum reaction conditions. The results indicated that the product was formed after

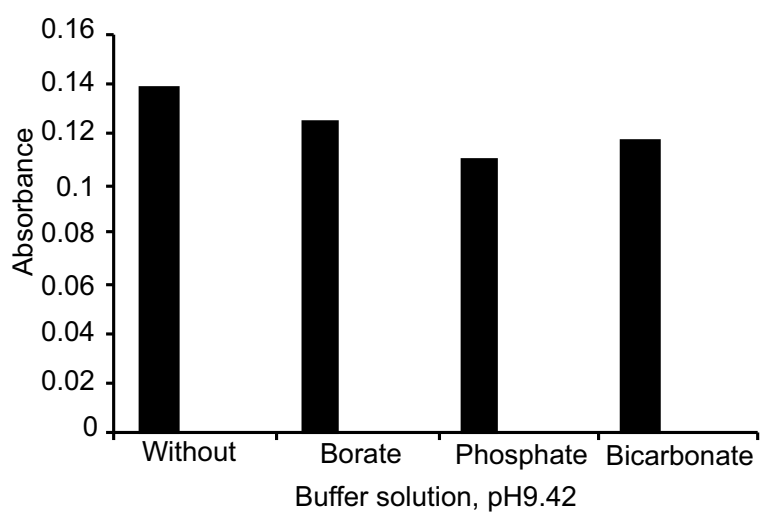

Fig. 2. Effect of buffer solutions on the absorbance of $10 \mu \mathrm{g} / \mathrm{mL}$ hydrolyzed paracetamol with 9-CA reagent. the addition of reagent immediately and reached its maximum absorbance at $40^{\circ} \mathrm{C}$ after $30 \mathrm{~min}$ and remain constant for 50 min after which the absorbance was decreased indicating dissociation (Fig. 5). Whereas, a decrease in absorbance with increased temperature was noticed indicating dissociation.

Quantitation. The results for the determination of paracetamol by 9-CA reagent are summarized in Table 1. Beer's law limits and molar absorptivity value were evaluated and indicated that the method is sensitive. The linearity was represented by the regression equation and the corresponding correlation coefficient for drug determined by the proposed method represents excellent linearity. The relative standard deviation (RSD) and accuracy (average recovery percentage ( $\operatorname{Rec} \%)$ ) for the analysis of four replicates of each three different concentrations for paracetamol indicated that the method is precise and accurate. Limit of detection (LOD) and limit of quantitation (LOQ) were calculated according

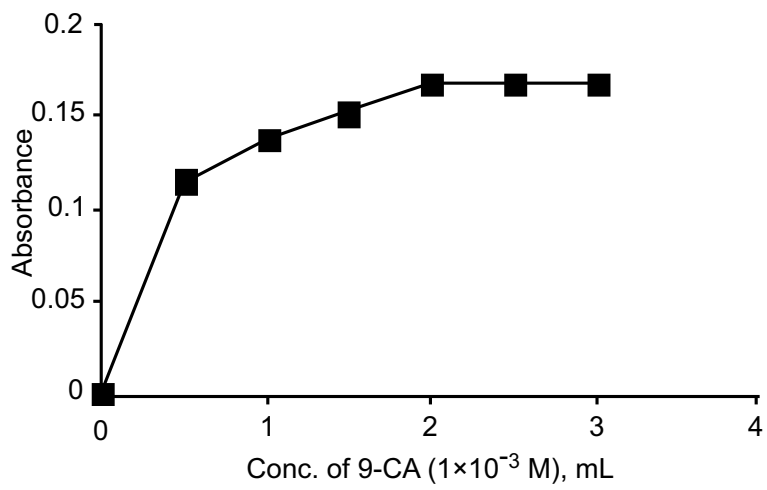

Fig. 3. Effect of 9-CA reagent concentration.

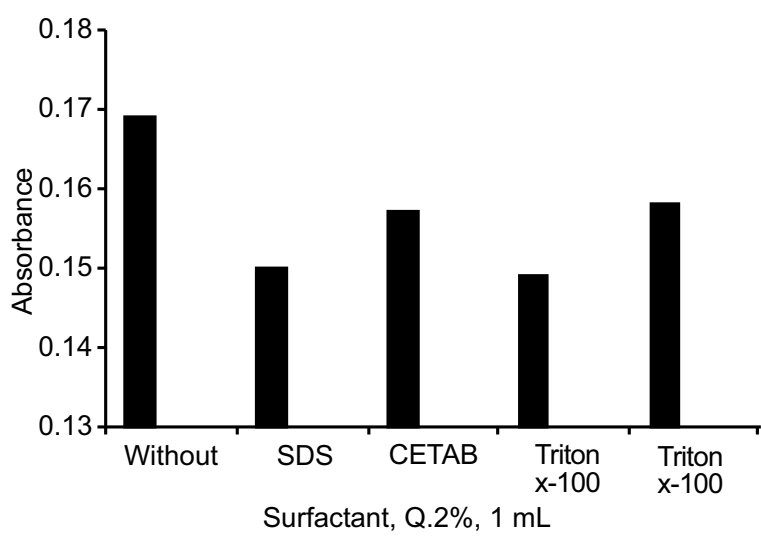

Fig. 4. Effect of surfactant on the absorption of $2.5 \mu \mathrm{g} / \mathrm{mL}$ of paracetamol. 


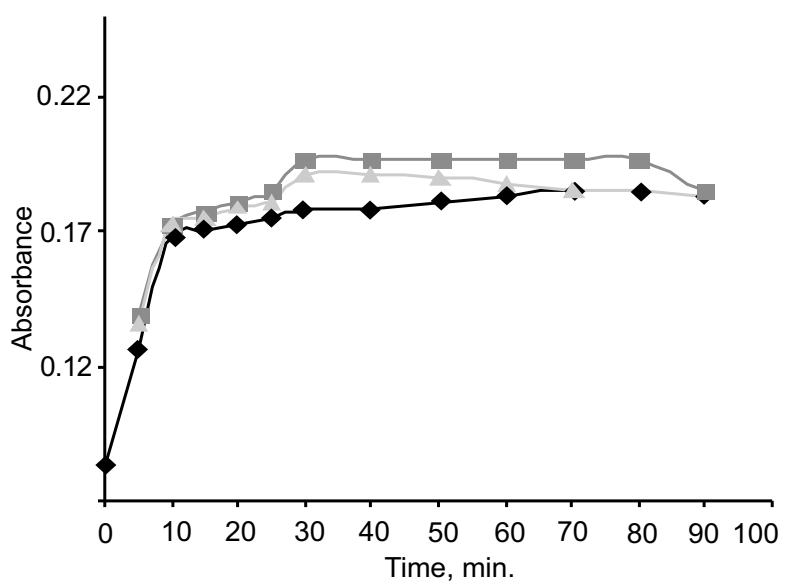

$\rightarrow$ R.T. $40^{\circ} \mathrm{C} \triangle 50^{\circ} \mathrm{C}$

Fig. 5. Effect of temperature and developing time on the absorption of $2.5 \mu \mathrm{g} / \mathrm{mL}$ paracetamol.

Table 1. Optical characteristics and statistical data for the proposed method

\begin{tabular}{ll}
\hline \hline Parameter & Paracetamol \\
\hline$\lambda_{\max }(\mathrm{nm})$ & 436 \\
Linearity range $(\mu \mathrm{g} / \mathrm{mL})$ & $0.25-11$ \\
Molar absorptivity $(\mathrm{L} / \mathrm{mol} / \mathrm{cm})$ & $5.3 \times 10^{3}$ \\
LOD $(\mu \mathrm{g} / \mathrm{mL})$ & 0.668 \\
LOQ $(\mu \mathrm{g} / \mathrm{mL})$ & 2.026 \\
Average recovery $(\%)^{*}$ & 99.27 \\
Correlation coefficient & 0.998 \\
Regression equation $(\mathrm{Y})^{* *}$ & \\
Slope, a & 0.018 \\
Intercept, b & 0.069 \\
RSD** & $\leq 2.82$
\end{tabular}

$*$ Average of four determinations; $* * Y=a \mathrm{X}+\mathrm{b}$, where: $\mathrm{X}$ is the concentration of paracetamol in $\mu \mathrm{g} / \mathrm{mL}$. to the following equations:

$$
\mathrm{LOD}=3.3 \sigma / \mathrm{b} \text { and } \mathrm{LOQ}=10 \sigma / \mathrm{b}
$$

where:

$\sigma$ is the standard deviation of five reagent blank determinations and $b$ is the slope of the calibration curve. The obtained results are in the accepted range below the lower limit of Beer's law range.

Study of interferences. The extent of interference by some excipients which often accompany pharmaceutical preparations were studied by measuring the absorbance of solutions containing a fixed amount of drug $(5.5 \mu \mathrm{g} /$ $\mathrm{mL}$ ) and various amounts of excipients in a final volume of $5 \mathrm{~mL}$. It was found that the studied excipients did not interfere seriously (Table 2). Slight positive interference was observed in the presence of a large excess of excipients. However, an error of $5.0 \%$ in the absorbance readings was considered tolerable. Typical results are given in Table 2. This was indicated that the method was free from interferences.

Nature of the coloured product and stability constant. Continuous variations introduced by Job's and molar ratio methods (Delevie, 1997) have been employed to establish the stoichiometry of the coloured product.

Job's method. A $1 \times 10^{-3} \mathrm{M}$. Standard solutions of hydrolyzed paracetamol and 9-CA reagent were used. A series of solutions were prepared in which the total volume of paracetamol and reagent was kept at $2 \mathrm{~mL}$. The reagents were mixed in various proportions diluted to volume in a $5 \mathrm{~mL}$ calibrated flask with absolute ethanol and the general procedure followed:

As shown in Fig. 6a, the result indicated that the stoichiometric composition of the product was 1:1 paracetamol: 9-CA. This indicated that aromatic amino the group presented in the hydrolyzed paracetamol ( $p$-aminophenol) was responsible for the formation of the product.

Table 2. Effect of excipients on the determination of $5.5 \mu \mathrm{g} / \mathrm{mL}$ paracetamol

\begin{tabular}{llllllll}
\hline \hline Excipients & \multicolumn{7}{c}{ Recovery \% of $5.5 \mu \mathrm{g} / \mathrm{mL}$ in the presence of excipient $(\mu \mathrm{g} / \mathrm{mL})$} \\
\cline { 2 - 7 } & 40 & 100 & 140 & 180 & 220 & 260 & 300 \\
\hline $\mathrm{NaCl}$ & 97.97 & 98.99 & 100 & 102.03 & 103.55 & 104.06 & 106.09 \\
Lactose & 98.48 & 99.49 & 100 & 101.52 & 104.55 & 105.56 & --- \\
Glucose & 101.52 & 102.53 & 103.03 & 103.54 & 104.04 & 105.05 & ---- \\
Acacia & 98.98 & 101.02 & 102.54 & 104.57 & 106.59 & ---- & ---- \\
Sucrose & 97.98 & 98.99 & 100.51 & 102.02 & 103.55 & 104.04 & 106.06 \\
\hline \hline
\end{tabular}


Mole ratio method. A $1 \times 10^{-3} \mathrm{M}$ 9-CA was added to the fixed volume $(1 \mathrm{~mL})$ of $1 \times 10^{-3} \mathrm{M}$ hydrolyzed paracetamol, then the solution was diluted to the mark in a $5 \mathrm{~mL}$ volumetric flask with absolute ethanol and the general procedure followed. The intersections of the obtained straight lines indicated the molar ratio of the product. As shown in Fig. 6b, the result also proved the formation of the 1:1 stochiometry.

Stability constant. The apparent stability constant was estimated by comparing the absorbance of a solution containing stoichiometric amounts of the paracetamol and 9-CA reagent (As) to one containing an excessive amount of 9-CA reagent (Am). The average conditional stability constant of the product was calculated, according to the $1: 1$ ratio, by the following equation:

$$
\begin{aligned}
& \mathrm{Kc}=1-\alpha / \alpha^{2} \mathrm{C} \\
& \alpha=\mathrm{Am}-\mathrm{As} / \mathrm{Am}
\end{aligned}
$$

where:

$\mathrm{Kc}$ is the stability constant $(1 \mathrm{~mol} / \mathrm{L}), \alpha$ the dissociation degree and $\mathrm{C}$ the concentration of the product which
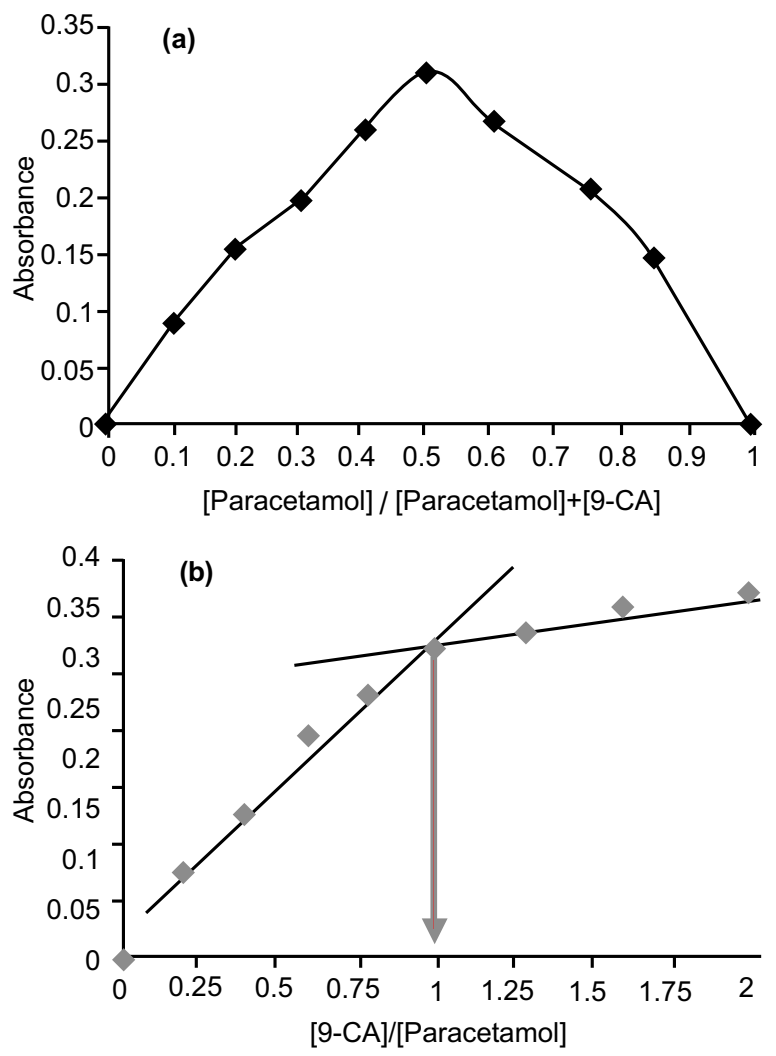

Fig. 6. Continuous variation (a) and mole ratio (b) plots for the hydrolyzed paracetamol 9-CA. is equal to the concentrations of paracetamol. However; the average of stability constant for three different concentration was found $6.34 \times 10^{5} 1 \mathrm{~mol} / \mathrm{L}$ for the paracetamol-9-CA product indicating high stability.

Reaction mechanism. The colour produced from the reaction of hydrolyzed paracetamol with 9-CA suggested that a free amino function in the molecule is necessary for the reaction. This finding is in agreement with the reaction of primary aromatic amines and/or aromatic hydroxylamine's with the acridine (Gammans et al., 1974; Stewart and Lotti, 1970; Shaw et al., 1969; Ray et al., 1969) to form highly coloured solutions. However, the reaction mechanism has been explained in Scheme (1).

Analytical applications. The proposed method was successfully applied to determine paracetamol in pharmaceutical tablets and suspension preparations. The obtained results were compared statistically by a Student's $t$-test for accuracy and a variance ratio $F$-test for precision with the British pharmacopeia procedure at the $95 \%$ confidence level with four degrees of freedom, as cited in Table 3, the results showed that the experimental $t$-test and $F$-test were less than the theoretical value $(t=3.182, F=9.12)$, indicating that there was no significant difference between the proposed method and official method.

Comparison of the methods. Table 4 shows the comparison between some of the analytical spectrophotometric methods using different reagents with the

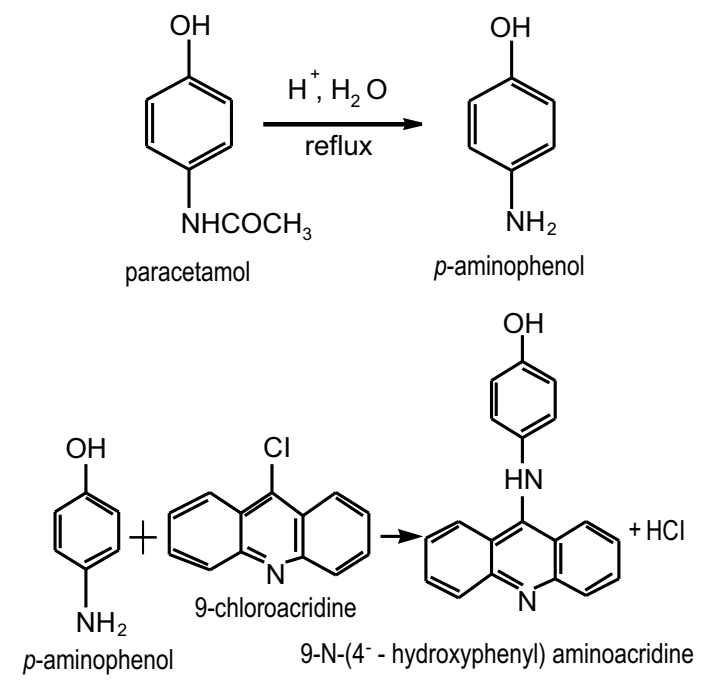

Scheme 1. Proposed reaction mechanism for assay of the paracetamol by 9 -CA. 
Table 3. Assay of paracetamol in pharmaceutical formulations

\begin{tabular}{|c|c|c|c|c|c|c|}
\hline Procedure applied & $\begin{array}{l}\text { Pharmaceutical } \\
\text { preparation }\end{array}$ & $\begin{array}{l}\text { Drug amount } \\
\text { present } \\
(\mu \mathrm{g} / \mathrm{mL})\end{array}$ & $\begin{array}{l}\text { Recovery } \\
(\%)\end{array}$ & $\begin{array}{l}\text { Average recovery } \\
(\%)\end{array}$ & $\begin{array}{l}\text { Drug content } \\
\text { found }(\mathrm{mg})\end{array}$ & $\begin{array}{l}\text { Certified value } \\
(\mathrm{mg})\end{array}$ \\
\hline \multirow{6}{*}{$\begin{array}{l}\text { Proposed 9-CA } \\
\text { method }\end{array}$} & paracetamol & 2.5 & 99.37 & \multirow{3}{*}{99.5} & \multirow{3}{*}{$\begin{array}{l}497.50 \\
(1.01,2.13)^{b}\end{array}$} & \multirow{3}{*}{500} \\
\hline & \multirow[t]{2}{*}{ tablet $^{\mathrm{S}}$} & 5 & 103.00 & & & \\
\hline & & 8 & 96.13 & & & \\
\hline & Paracetamol & 2.5 & 97.72 & \multirow{3}{*}{98.66} & & \multirow{3}{*}{125} \\
\hline & \multirow[t]{2}{*}{ Oral suspension $\mathrm{S}$} & 5 & 101.12 & & \multirow{2}{*}{$\begin{array}{l}123.33 \\
(2.47,2.08)^{\mathrm{b}}\end{array}$} & \\
\hline & & 8 & 97.13 & & & \\
\hline British & Paracetamol & 7.5 & 101.00 & & 05.00 & \multirow[t]{2}{*}{500} \\
\hline $\begin{array}{l}\text { Pharmacopoeia } \\
\text { tablet }\end{array}$ & & & & & & \\
\hline
\end{tabular}

Table 4. Comparison of the proposed method with other spectrophotometric methods

\begin{tabular}{|c|c|c|c|c|}
\hline \multirow{3}{*}{$\begin{array}{l}\text { Analytical } \\
\text { parameters }\end{array}$} & \multicolumn{4}{|c|}{ Reagent } \\
\hline & \multirow{2}{*}{$\begin{array}{l}\text { Present method } \\
\text { 9-CA }\end{array}$} & \multicolumn{3}{|c|}{ Literature method } \\
\hline & & $\begin{array}{l}\text { sodium bismuthate, } \mathrm{HCl} \\
\text { (Kumar et al., 2012) }\end{array}$ & $\begin{array}{l}\text { 3-chloro-7-hydroxy-4-methyl- } \\
\text { 2H-chromen-2-one } \\
\text { (Divya et al., 2013) }\end{array}$ & $\begin{array}{l}\text { Fe(III)-2,4,6-tris(2-pyridyl)- } \\
\text { S-triazine } \\
\text { (Liu and Oka, 1980) }\end{array}$ \\
\hline$\lambda_{\max }(\mathrm{nm})$ & $\begin{array}{l}436 \\
\text { alkaline }\end{array}$ & $\begin{array}{l}550 \\
\text { acidic }\end{array}$ & $\begin{array}{l}545 \\
\text { Alkaline }\end{array}$ & $\begin{array}{l}593 \\
\text { acidic }\end{array}$ \\
\hline Temp. $\left({ }^{\circ} \mathrm{C}\right)$ & 40 & RT & 40 & RT \\
\hline $\begin{array}{l}\text { Development } \\
\text { time (min) }\end{array}$ & 30 & Immediately & 10 & 15 \\
\hline $\begin{array}{l}\text { Stability } \\
\text { period (min) }\end{array}$ & 50 & - & - & 15 \\
\hline $\begin{array}{l}\text { Beer's law } \\
(\mu \mathrm{g} / \mathrm{mL})\end{array}$ & $0.25-11$ & $100-300$ & $10.0-60.0$ & $25-400$ \\
\hline $\begin{array}{l}\text { Molar } \\
\text { absorptivity } \\
(\mathrm{L} / \mathrm{mol} / \mathrm{cm})\end{array}$ & $5.3 \times 10^{3}$ & 100.0 & $1.2 \times 10^{3}$ & $1.2 \times 10^{3}$ \\
\hline Recovery (\%) & 99.27 & 99.8 & $\leq 102.3$ & $\leq 106.6$ \\
\hline RSD (\%) & $\leq 2.82$ & 1.70 & $\leq 1.50$ & - \\
\hline Application & $\begin{array}{l}\text { Tablet, } \\
\text { suspension }\end{array}$ & Tablet & Tablet & Serum, Plasma \\
\hline Disadvantages & Need heating & Very poor sensitivity & Using an organic solvent & Suffered from interferences \\
\hline
\end{tabular}

proposed method using 9-CA reagent. As seen in Table 3, the present method is more sensitive than the cited methods, accurate, have no interferences and carried on an aqueous medium.

\section{Conclusion}

A simple, precise, selective and sensitive spectrophotometric method was developed for the determination of microgram amounts of paracetamol-based on the reaction 
of hydrolyzed paracetamol with 9-CA reagent to form a coloured product having maximum absorption at $436 \mathrm{~nm}$ in an aqueous medium. The proposed method was successfully applied for the assay of the pharmaceutical formulations as tablets and suspension of paracetamol.

Conflict of Interest. The authors declare no conflict of interest.

\section{References}

Afshari, J.T., Liu, T.Z. 2001. Rapid spectrophotometric method for the quantitation of acetaminophen in serum. Analytica Chimica Acta Journal, 443: $165-$ 169.

Al-Abachi, M.Q., Sinan, R., Falah, Z. 2008.Batch and flow-injection spectrophotometric methods for determination of paracetamol in pharmaceutical preparations by coupling with diazotized 4-nitroaniline. Iraqi Journal of Science, 49: 12-20.

Al-Enizzi, M.S. 2002. Development of a spectrophotometric method for determination of paracetamol, histamine and some sulpha drugs. M.Sc.Thesis, Mosul University, Mosul, Iraq.

Al-Esawati, F.M.J. 2002. Development of spectrophotometric methods for the determination of some phenolic compounds and drugs via organic oxidative coupling reaction. M.Sc.Thesis, Mosul University, Mosul, Iraq.

Al-Ward, H.S.J. 2002. Analytical pharmaceutical applications on oxidative coupling reaction. M.Sc. Thesis, University of Baghdad, Baghdad, Iraq.

British Pharmacopoeia, 2009. Medicines and healthcare products regulatory agency; London, United Kingdom, Paracetamol, 9634 pp.

Chen, G., Ye, J., Bao, H., Yang, P. 2002. Determination of the rate constants and activation energy of acetaminophen hydrolysis by capillary electrophoresis. Journal of Pharmaceutical and Biomedical Analysis, 29: 843-850.

Darak, V., Karadi, A.B., Raju, S.A., Arshad, M.D., Ganure, A.L. 2012. Development and validation of HPLC method for determination of mesalamine in tablet dosage forms. Pharmaceutical Science Monitor, 3: 74-81.

Delevie, R. 1997. Principle of Quantitative Chemical Analysis, 498 pp., McGraw-Hill, New York, USA.

Divya, K., Narayana, B., Sapnakumari, M. 2013. Sensitive spectrophotometric determinations of paracetamol and protriptyline $\mathrm{HCl}$ using 3-chloro-
7- hydroxy-4- methyl-2H-chromen-2-one. ISRN Spectroscopy, 1-6.

Easwaramoorthy, D., Yu, Y.C., Huang, H.J. 2001. Chemiluminescence detection of paracetamol by a luminol-permanganate based reaction. Analytica Chimica Acta, 439: 95-100.

European Pharmacopoeia, 2014. Quality of Medicines and Healthcare of the Council of Europ, Paracetamol, 2: 2963.

Gammans, R.E., Stewart, J.T., Sternson, L.A. 1974. Colourimetric determination of $\mathrm{N}$-aryl hydroxyl amines with 9-chloroacridine. Analytical Chemistry, 46: 620-621.

Hamm, J. 2000. Acute acetaminophen overdose in adolescents and adults. Critical Care Nurse, 20: 69-74.

Kumar, G.P., Kumar, G.B., Sekhar, C.T., Murthy, S.B. 2012. Spectrophotometric determination of paracetamol using sodium bismuthate as chromogen. International Journal of Research in Chemistry and Environment, 2: 231-235.

Liu, T.Z., Oka, K.H. 1980. Spectrophotometric screening method for acetaminophen in serum and plasma. Clinical Chemistry, 26: 69-71.

Muszalska, I., Zajac, M., Worbel, G., Nogowska, M. 2000. Redox methods validation of paracetamol and ascorbic acid in pharmaceutical preparations. Acta Poloniae Pharmaceutica, 57: 27-32.

Nagendra, P. 2011. Spectrophotometric estimation of paracetamol in bulk and pharmaceutical formulations. E-Journal of Chemistry, 8: 149-152.

Nigovic, B., Simunic, B. 2003. Determination of 5aminosalicylic acid in pharmaceutical formulation by differential pulse voltammetry. Journal of Pharmaceutical and Biomedical Analysis, 31: 169-174.

Pastorini, E., Locatelli, M., Simoni, P., Roda, A., Roda, G. 2008. Development and validation of an HPLCESI-MS/MS method for the determination of 5aminosalicylic acid in human plasma. Journal of Pharmaceutical Sciences Sciences, 872: 99-106.

Ray, A.B., Stewart, J.T., Fackler, W.B. 1969. Colourimetric determination of some sulfonamides with 9-chloroacridine. Journal of Pharmaceutical Sciences, 58: 1261-1262.

Raymond, T.I, Andona, M.I., Royality, S., Winifred, U.N. 2017. Spectrophotometric determination of paracetamol in drug formulations with 1-naphthol. International Journal of Advanced Chemistry, 5: 86-90. 
Ruengsitagoon, W., Liawruangrath, S., Townshend, A. 2006. Flow injection chemiluminescence determination of paracetamol. Talanta, 69: 976-983.

Sharma, C.V., Mehta, V. 2014. Paracetamol: mechanisms and updates. BJA Education, 14: 153-158.

Shaw, T.D., Stewart, J.T., Ray, A.B. 1969. Spectrophotometric determination of primary aromatic amines with 9-chloroacridine. Analytical Chemistry, 41: 360-362.

Shrestha, B.R., Pradhananga, R.R. 2009. Spectrophotometric method for the determination of paracetamol. Journal of Nepal Chemical Society, 24: 39-44.

Song, H., Chen, T.S.2001, p-Aminophenol induced liver toxicity: tentative evidence of a role for acetaminophen. Journal of Biochemical Molecular Toxicology, 15: 34-40.

Stewart, J.T., Lotti, D.M. 1970. Improved colourimetric determination of primary aromatic amines with 9-chloroacridine. Journal of Pharmaceutical
Sciences, 59: 838-840.

Sultan, S.M., Al-Zamil, I.Z., Al-Rahman, A.M. 1986. Use of cerium(IV) sulphate in the spectrophotometric determination of paracetamol in pharmaceutical preparations. Analyst, 111: 919-921.

Tetsuo, I., Masayoshi, T., Toyozo, I., Shuchi, L. 1975. Studies on analysis of pharmaceutical preparations. XXIX. Colourimetric determination of acetaminophen in anti-cold pharmaceutical preparations. Japaneze Journal of Toxicology and Environmental Health, 21: 313-317.

The Japanese Pharmacopoeia. 2016. Ministry of Health, Labour and Welfare Paracetamol, $17^{\text {th }}$ ed., $363 \mathrm{pp}$.

The United States Pharmacopeia. National formulary. 2013. Pharmacopeial Convention, vol. 2, Rockville (MD), USA.

Tungkananuruk, K., Tungkananuruk, N., Burns, D.T. 2005. Cyclic voltammetric determination of acetaminophen in paracetamol tablets. KMIT Science and Technology Journal, 5: 547-551. 